\title{
Um projeto de rede de bibliotecas para as escolas públicas estaduais de Santa Catarina, Brasil: relato de experiência(s)
}

Eliane Fioravante Garcez

Gisela Eggert-Steindel

Doutoranda no Programa de Pós-Graduação em Ciência da Informação, da Universidade Federal de Santa Catarina (PGCIN/UFSC).Bolsista da CAPES - Proc. no BEX 0492/15-9.Mestre em Ciência da Informação pelo PGCIN/UFSC. Especialista em Gestão do Conhecimento (UFSC), Especialista em Gestão de Bibliotecas (UDESC)

Doutora em Educação pela Universidade de São Paulo (USP). Mestre em Ciência da Informação pela Universidade Federal de Minas Gerais (UFMG). Especialista em Informação para a indústria pela Universidade Federal de Santa Catarina (UFSC) na qual também graduou-se em Biblioteconomia e Documentação. Professora no Centro de Ciências Humanas e da Educação da Universidade do Estado de Santa Catarina (UDESC)

José Paulo Speck Pereira

Bibliotecário/servidor público. Coordenador da Divisão de Assistência aos Usuários da Biblioteca Central da Universidade Federal de Santa Catarina.Atuou como secretário-executivo do Fórum Catarinense do Livro e da Leitura, coletivo promotor de políticas públicas para o livro, leitura, literatura e bibliotecas no estado catarinense. Atuou como presidente da Associação Catarinense de Bibliotecários (ACB) entre 2012 e 2013

Gyance Carpes

Mestre em Ciência da Informação pela Universidade Federal de Santa Catarina (UFSC). Especialista em Gestão de Bibliotecas pela Universidade do Estado de Santa Catarina (UDESC) Bacharel em Biblioteconomia pela Universidade do Estado de Santa Catarina (UDESC).Presidente do Conselho Regional de Biblioteconomia 14. Região - Gestão 2012-2014.

http://dx.doi.org/10.1590/1981-5344/2468

Perspectivas em Ciência da Informação, v.21, n.2, p.237-262, abr./jun. 2016 
Discute percursos da implantação de uma rede de bibliotecas para as escolas públicas do estado de Santa Catarina e sobre a criação do cargo de bibliotecário vinculado ao Quadro do Magistério Público deste Estado. As diferentes ações da categoria profissional para a criação do cargo de bibliotecário para atuar nessas escolas, o movimento dessa classe profissional para tal intento desde os anos 90 do século XX. Apresenta a proposta da categoria resultado das várias discussões (e elaboração de propostas de projetos) que vêm ocorrendo desde 2003. A aprovação da Lei 12.244/2010 motivou, em 2012, a Secretaria da Educação propôr uma reunião com a categoria profissional com intuito, em uma ação conjunta, a elaboração de uma proposta de criação do cargo de bibliotecário para as 1.112 escolas estaduais. Esse projeto prevê não apenas a criação do cargo, cerca de 300, mas o funcionamento de uma rede de bibliotecas estruturada em três pontos estratégicos para a atuação desse profissional, assim desenhado: Órgão Central, Secretarias Regionais e Entidades Escolares - nesse tripé sustenta-se a rede ora proposta.

Palavras-Chave: Biblioteca Escolar; Bibliotecário; Rede de Bibliotecas; Santa Catarina (Brasil).

\section{A library network project for public schools state of Santa Catarina, Brazil: experience report (s)}

Discusses the deploying a network of libraries to public schools in the state of Santa Catarina and the creation of the post of librarian linked to the Framework of the Public Magisterium this Estado. As well different actions of the professional category for creating the librarian position to act these schools, the movement of this professional class for this purpose since the 90s of XX century. Presents the proposal of the category result of several discussions (and preparation of project proposals) that have occurred since 2003. The approval of Law 12.244/2010, led in 2012 to the Education Department proposed a meeting with the professional category, in order to joint action, to draw up a proposal for a librarian job creation for 1.112 schools estaduais. This project includes not only the creation of the post 300, but the operation of a network of libraries structured into three strategic points to the role of this 
professional, well designed: Central Agency, Regional Secretariats and School Entities - this tripod holds up the network proposed here.

Keywords: School Library; Libraria; Libraries Network; Santa Catarina (Brazil).

Recebido em 19.06.2015 Aceito em 17.05.2016

\section{Introdução}

As bibliotecas escolares (BE) são espaços educativos imprescindíveis na formação das pessoas? Se abordássemos a população brasileira que respostas obteríamos?

Em Repensando a escola: um estudo sobre os desafios de aprender, ler e escrever, Ireland (2007, p. 89) expressa que no Brasil há é "um fazde-conta que existe biblioteca na escola". Quando não falta biblioteca, faltam livros nela ou, então, permanece fechada por falta de profissional.

Em 2008, o estudo Programa Nacional Biblioteca da Escola (PNBE): leitura e bibliotecas nas escolas públicas brasileiras descreveu assim a realidade das bibliotecas:

Os espaços de leitura nas escolas pesquisadas apresentaram-se muito variados. Dos espaços adaptados, pequenos, acanhados, mal iluminados, "depósitos de livros" amontoados, desorganizados, às bibliotecas generosas, construídas especificamente para sua função e finalidade, uma gama de modelos e de realidades foi encontrada. Salas de leitura acopladas a bibliotecas, em menor número, ou salas de leitura apenas, sem bibliotecas. $E$ o que dizer dos armários "armarioteca", no dizer de um diretor baiano - em substituição à biblioteca? Uma característica tristemente representativa desses variados espaços e desenhos de ambientes de leitura esteve simbolizada pela chave - a síntese do inacessível, do inatingível -, que vedava inúmeros espaços e acessos: de salas de leitura, de bibliotecas, de armários, todos eles fechados, com portas escondendo o enigma atrás de muralhas intransponíveis ao acesso e fruição dos usuários - estudantes, professores, comunidade. (BRASIL, 2008, p. 86).

Em 2011, o estudo intitulado Avaliação das bibliotecas escolares no Brasil (BRASIL, 2011) apontou que: 
Bibliotecas escolares, como qualquer nome que tenham, são uma realidade nas escolas brasileiras, ainda que estejam longe de cumprir o papel que Ihes caberia para emancipar, autonomizar e encantar os leitores em formação, que a escola acolhe a cada dia mais. (BRASIL, 2011, p. 15).

E, ainda, que...

[...] se está longe de ter nesses espaços uma organização, concepção e dinamização que favoreçam o uso competente e frequente da biblioteca escolar e de seus acervos e materiais pelos usuários da escola. Embora as redes públicas já desenvolvam ações para o uso competente e freqüente da biblioteca escolar e de seus acervos e materiais pelos usuários da escola. (BRASIL, 2011, p. 102).

A existência e o oferecimento de serviços bibliotecários (com uma estrutura, acervo, profissionais qualificados, dentre outros), no espaço escolar estão relacionados à perspectiva de um melhor nível de práticas formadoras e autoformadoras para a desenvoltura, competência e autonomia do indivíduo em sociedade. A comunidade escolar deve encontrar nesse espaço, de forma ampliada e diversificada, aquilo que é tratado na sala de aula e outras opções de leitura para além desse propósito primeiro da biblioteca escolar, que é o de atender a demanda de uma grade curricular. A biblioteca escolar precisa ofertar à comunidade escolar acesso à literatura, às notícias diárias - que ocorram no contexto onde a escola está inserida, e de outros contextos conectados com este - , espaço para o encontro de pessoas e ideias dentre outras tantas possibilidades. Se, como diz Paulo Freire em seu livro A Importância do Ato de Ler (FREIRE, 1997) a leitura do mundo precede a leitura da palavra, por certo que a possibilidade de leitura na biblioteca escolar aumenta a leitura do mundo; visão/compreensão sobre ele e sobre o/s indivíduo/s nele. Neste sentido, a biblioteca escolar deve estar no discurso e na ação dos gestores públicos.

Entretanto, com raríssimas excessões, as bibliotecas escolares brasileiras têm revelado na sua história uma contradição: são importantes na instrução escolar e formação geral dos indivíduos, mas têm recebido pouca atenção dos gestores públicos. É preciso conseguir cúmplices na esfera pública para a causa da biblioteca escolar e desanuviar a ideia de tratar-se de questão de interesse restrito à área da biblioteconomia.

A International Federation of Library Associations and Institutions (IFLA) e a Organização das Nações Unidas para a Educação, Ciência e Cultura (UNESCO) publicaram o Manifesto Ifla/Unesco para a Biblioteca Escolar (IFLA, 1999), as Diretrizes para a Biblioteca Escolar (IFLA, 2002a), - Manifesto sobre Internet (IFLA, 2002b) e suas Diretrizes (IFLA, 2006). No conjunto esses documentos servem para orientar governos, gestores e profissionais para que seja viabilizada uma política de acesso à informação 
a partir da escola, mas de chamar a atenção das autoridades para a responsabilidade que têm pela situação das bibliotecas escolares públicas.

A biblioteca escolar é essencial a qualquer tipo de estratégia de longo prazo no que respeita a competências à leitura e escrita, à educação e informação e ao desenvolvimento econômico, social e cultural. A responsabilidade sobre a biblioteca escolar cabe às autoridades locais, regionais e nacionais, portanto deve essa agência ser apoiada por política e legislação específicas. Deve também contar com fundos apropriados e substanciais para pessoal treinado, materiais, tecnologias e instalações (IFLA, 1999, p. 2).

Em nosso país, o governo federal promulgou, em 2010, a Lei no 12.244 (BRASIL, 2010) prevendo uma universalização das bibliotecas escolares até 2020. Antes dessa promulgação, a classe bibliotecária de Santa Catarina procurou obter do Governo estadual um compromisso para melhorar as condições de suas bibliotecas escolares. E, recentemente, após esta lei, elaborou um novo projeto bibliotecário para as BE.

Neste cenário introdutório quer-se nesse artigo apresentar e discutir a atual BE, especificamente no estado de Santa Catarina, ao socializar para a categoria profissional e gestores públicos deste Estado um projeto bibliotecário para as BE apresentado ao Secretario estadual da Educação no início de 2013.

Incluindo esta introdução, o presente texto está estruturado em cinco itens. No item dois, discutimos a biblioteca escolar do estado de Santa Catarina na agenda governamental ao longo do século XX e os questionamentos de suas ações voltadas à biblioteca escolar do século XXI. No item três, discorremos sobre os percalços e os avanços no processo de construção do projeto em questão. No item quatro, tratamos de expor as intenções que levou o grupo a conceber o projeto cujo detalhamento é apresentado no Anexo A (que integra o Projeto de Lei Complementar para a criação do cargo de bibliotecário e seus seis anexos) e suas justificativas (criação de 300 cargos de bibliotecário, suas atribuições, salários, carga horária, plano de carreira, os critérios de distribuição desses cargos em 1.112 unidades escolares distribuídas por 295 municípios, dentre outros). Por fim, no item cinco, destacamos a importância de se estabelecer interlocuções nas diferentes esferas políticas e de socializar esse projeto para as bibliotecas escolares para que possa ser conhecido e discutido.

\section{A biblioteca das escolas na agenda governamental}

Para muito antes do Manifesto IFLA/UNESCO para a Biblioteca Escolar (1999), a biblioteca escolar é objeto de investigação da História, da Biblioteconomia, da Educação e, mais recentemente, da História da Educação, particularmente no tocante aos estudos dos impressos. 
Os estudos empreendidos sobre o tema no campo da Biblioteconomia elegem, de modo mais frequente, análises técnicas com referência a usuário, acervo, planejamento e sua gestão. Neste âmbito, podem-se citar alguns pesquisadores, como Luis Augusto Milanesi, Iara Conceição Bitencourt Neves e Bernadete Santos Campello. No campo da Biblioteconomia, em fins da década de 80 e com mais ênfase nos anos 90, foi produzida uma bibliografia nacional preocupada em assinalar a inexistência de BE no sistema educacional brasileiro. Citamos o trabalho de Silva (1995), que entende que a palavra que melhor define biblioteca escolar no Brasil é "silêncio". Machado (2002, p.13), de modo mais veemente o corrobora, ao acrescentar que "é realmente um silêncio quase sepulcral, que até faz sentido, pois a biblioteca escolar no Brasil está praticamente morta, faltando apenas enterrá-la'" (sic).

No campo da História da Educação, há estudos pautados em fontes documentais, relatórios e depoimentos que buscam e apontam outros olhares para a biblioteca escolar. A tese de doutorado $O$ exercício disciplinado do olhar: livros, leituras e práticas de formação docente no Instituto de Educação do Distrito Federal (1932-1937), de Diana Gonçalves Vidal (1995), mostra uma gênese da biblioteca escolar, a partir das reformas do ensino pautadas na Escola Nova e realizadas por Fernando de Azevedo (1928-1930) e Anisio Teixeira (1931-1935). O estudo mostra que a escolanovísta criou duas categorias de biblioteca: a biblioteca do professor, instada à complementar as atividades de estudo e preparo de suas atividades e a biblioteca do aluno a qual deveria ser um espaço de estudo e sociabilidade. Pode-se inferir que esses educadores colocaram a biblioteca escolar na agenda governamental, a partir da década de 1930. Nesta mesma linha, a professora e pesquisadora Ana Chrystina Venâncio Mignot (2002) na sua obra Baú de Memórias, Bastidores de Histórias: o legado pioneiro de Armanda Álvaro Alberto, de modo magistral mostra que a biblioteca da escola brasileira tem seu início na escola primária em um movimento nacional e local.

Nesta trilha, é necessário mencionar o estudo seminal em Santa Catarina realizado por Alzemi Machado (2002), A Implantação de Bibliotecas Escolares na Rede de Ensino de Santa Catarina (décadas de 30 e 40). Neste período o Brasil vivia o movimento da Escola Nova ou Escola Ativa, um ideal de escolarização europeu do XIX que defendia uma educação calcada no conhecimento das novas ciências.

No movimento escolanovista barriga-verde estavam envolvidos intelectuais do Departamento Estadual de Educação das décadas de 1930 e 1940, tendo a frente Luiz Sanchez Bezerra da Trindade (BOMBASSARO, 2007). A partir de fontes documentais do, então, Departamento de Educação de Santa Catarina, a Reforma Trindade (1935) institucionaliza a biblioteca da escola, ratificada pela Reforma Elpídio Barbosa (1946-1971) na educação pública de Santa Catarina (SANTA CATARINA, 1946). A Reforma Trindade inovou ao criar o Departamento de Educação e as ditas subdiretorias, como a Subdiretoria de Bibliotecas, Museus e Radiodifusão. Assim, se estabelece em nosso Estado uma nova atividade profissional na 
escola, através dos cargos de Professora Bibliotecária e de Professora Encarregada de bibliotecas escolares. As bibliotecas propostas deveriam inicialmente ser instaladas nos Grupos Escolares Modelo, na época nos municípios de Florianópolis e Lages.

Na Reforma Elpídio Barbosa, implantada pelo Decreto no 3.735/46 (SANTA CATARINA, 1946), a partir da orientação do Decreto Federal no 8.529, de 2 de janeiro do mesmo ano (BRASIL, 1946), a biblioteca escolar tem uma articulação direta com as demais instituições complementares, denominadas Associações Escolares, como: liga pró-língua nacional; caixa escolar; cooperativa escolar; clube agrícola escolar; pelotão de saúde; biblioteca escolar; jornal escolar; clube de leitura; liga da bondade; círculo de pais e professores, etc.

Nas décadas de 1940 a 1960 a biblioteca escolar teve presença significativa na agenda do ensino público catarinense. A decáda de 50, especificamente, foi o período de maior criação dessas unidades no estado. Contudo, a partir da década de 60, e mais na de 70, as políticas públicas fazem com que as $B E$ deem lugar à biblioteca pública (EGGERTSTEINDEL; FONSECA, 2010). Segundo esses autores:

[...] esse tipo de biblioteca, o seu público e por que não dizer seu acervo passa a ter abrigo nas bibliotecas públicas. Este cenário tem indícios nos dados catalogados, isto é naquela década registrou-se 550 bibliotecas existentes em 197 municípios. Em outras palavras, ocorreu uma diminuição de bibliotecas nas escolas da Rede de Ensino Público em Santa Catarina. (EGGERT-STEINDEL; FONSECA, 2010, p. 260).

A inexistência de uma política pública nos anos 70 para a $B E$ culminou com o que se tem hoje; bibliotecas públicas na função da BE. $O$ estudo de doutoramento de Oliveira (1999) sobre a biblioteca pública, a partir da análise dos documentos do Instituto Nacional do Livro (INL), mostra que a biblioteca pública assumia papéis de acordo com o perfil profissional da direção desse Instituto. De 1970 a 1974, a bibliotecária Maria Alice Barroso transformou a biblioteca pública em biblioteca escolar, quadro que permanece na realidade catarinense e brasileira.

Hoje, parece-nos que o país vive um momento mais propício para se discutir a BE nas diferentes esferas políticas (o poder público, os professores e sindicato, os bibliotecários e seus órgãos representativos, 0 Legislativo, as associações de pais e professores, os conselhos comunitários, dentre outros), nos diferentes estados e municípios. É mais propício por termos à disposição fundamentos que nos auxiliam na argumentação.

A BE é um espaço, uma possibilidade de acesso à informação ou, como enfatizam Silva e Siqueira (2014, p. 40), "um dos tópicos pertinentes aos 'Direitos Humanos' hodiernos, dada a relevância da sua função social e suas possibilidades de influir positivamente na formação educacional, na promoção da cidadania e dos valores éticos fundamentais 
para a convivência fraterna na complexa era digital." $E$, hoje, temos a Lei no 12.244 (BRASIL, 2010), para que no Brasil o acesso à BE seja direito de todos.

Cientes de um contexto mais promissor à BE, em 2012, uma Comissão formada por bibliotecários e professores se reuniu com o intuito de elaborar um projeto para essas bibliotecas, quando era registrada a existência de 1.112 unidades escolares vinculadas à administração pública estadual. Dessas, não se sabia quais tinham biblioteca, tampouco a situação desses espaços. Apenas que em nenhuma dessas escolas havia bibliotecário, mas professor readaptado ${ }^{1}$. Além do quantitativo de escolas, conhecíamos suas denominações, em qual das 36 Secretarias Regionais de Educação estavam vinculadas, as modalidades de ensino oferecidas, localização e quantitativo de alunos. Estes dados foram fundamentais quando a comissão, composta pelos autores deste artigo, encarregada de estudar um projeto bibliotecário definindo quais escolas receberiam bibliotecários dos 300 cargos previstos para criação e atuação nessa rede estadual. A Comissão não partiu do zero, mas pautou suas dicussões na trilha dos esforços envidados em anos anteriores pela classe bibliotecária catarinense, objeto do próximo item, com o intuito de alavancar a biblioteca escolar.

\section{Percalços e avanços na construção da biblioteca escolar: esforços da classe bibliotecária}

Neste capítulo apresentamos recortes de diferentes esforços que refletem o movimento da categoria profissional local para com a biblioteca escolar, uma vez que os mesmos possibilitaram o direcionamento para a concepção do projeto em questão.

Em 2003 houve uma mobilização da categoria por ocasião da publicação de Portaria 003/SED de 04/04/2003 (SANTA CATARINA, 2003), do Secretário da Educação, que tratava de readaptar professores para as bibliotecas e outros espaços das Escolas de Ensino Fundamental (EEF), Escolas de Ensino Médio (EEM) e das Escolas de Educação Básica (EEB) com mais de 400 alunos em dois ou três turnos de funcionamento. Segundo Garcez (2014, p. 6), foi a partir desse momento que "o Governo acenou para a possibilidade de transformar 300 cargos de Assistente Educacional do Quadro do Magistério [SANTA CATARINA, 1992] em cargos de bibliotecário." Dá-se início a uma conversa que levou a categoria bibliotecária à elaboração de um projeto bibliotecário para as escolas estaduais. Em outubro desse ano, durante mesa de debate Espaços Públicos, Informação e Cidadania, promovida pelo III Fórum Estadual de Bibliotecas Escolares, o Secretário da Educação "Reconhece a necessidade da criação do cargo de bibliotecário escolar no Estado, meta para início

\footnotetext{
${ }^{1}$ Conforme dispõe o artigo 48 da Lei no 6.844/1986 (SANTA CATARINA, 1986), a readaptação é recurso utilizado pelo professor que está temporariamente impossibilitado de exercer a docência por motivo de saúde. Durante esse período esse profissional pode exercer outra atividade no espaço da escola desde que seja coerente com a sua função inicial.
} 
em 2004" (FÓRUM..., 2003/2004, [p. 7]), contudo, as interlocuções esfriam.

Julgando que a luta pela BE precisava do apoio manifesto da sociedade catarinense, em abril de 2005, a categoria decidiu pela coleta de assinaturas da população local para a formalização de um abaixoassinado a ser anexado em argumentos posteriores, quer no Executivo, quer no Legislativo. Essa atividade ocorreu no dia 22 de abril de 2005 no calçadão da Rua Felipe Schmidt, no Centro de Florianópolis, e contou com representantes da categoria profissional na Universidade Federal de Santa Catarina (UFSC), Universidade do Estado de Santa Catarina (UDESC), Universidade do Sul de Santa Catarina (UNISUL), Grupo de Bibliotecários da Área Escolar de Santa Catarina (GBAE/SC) e da Rede de Bibliotecas Escolares da Prefeitura Municipal de Florianópolis.

Em 2006, a professora Elizabete Anderle, então Secretária de Estado da Educação, anuncia durante o V Fórum Estadual de BE que "o Projeto de Lei Complementar da criação do cargo de bibliotecário será assinado na próxima segunda-feira (23/10/2006) pelo governador Luiz Henrique da

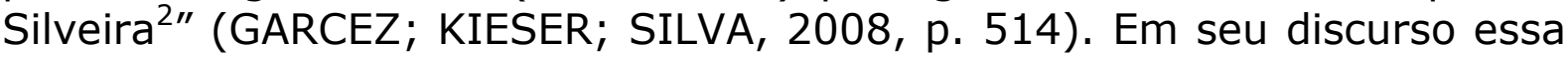
professora externa que:

as escolas de Santa Catarina, por muito tempo, tiveram e ainda têm bibliotecas mortas, por falta de profissionais bibliotecários nestes espaços, livros, e ações pedagógicas. Reforça a assinatura do Projeto de Lei Complementar para a criação do cargo de bibliotecário (...). Esta lei levará a promoção de concursos para a abertura de vagas no Quadro do Estado. Inicialmente devem ser oferecidas 50 vagas para as Secretarias Regionais do Estado, cujo papel será o de fomentar as bibliotecas escolares e capacitar os profissionais nelas existentes. (GARCEZ; KIESER; SILVA, 2008, p. 515).

Nesse pronunciamento vemos algo novo. A proposição inicial do Executivo de criar 300 cargos de bibliotecário é alterada para 50 cargos com atuação concentrada nas 36 Secretarias Regionais do Estado. Todavia, a ocorrência de alguns percalços, cujas razões não estão documentadas, fez com que o projeto de lei não fosse encaminhado ao Legislativo para votação após o interstício eleitoral. Luis Henrique da Silveira é releito para a gestão 2007-2010, contudo a conversa com os bibliotecários pouco mudou nesse novo mandato.

Em maio de 2010 o Governo Federal promulga a Lei no 12.244 (BRASIL, 2010), a qual prevê para dez anos a universalização de bibliotecas escolares. Em julho, tramita na Assembleia Legislativa do Estado de Santa Catarina (ALESC) o Projeto de Lei Complementar PLC/0039.0/2010 (SANTA CATARINA, 2010) para a criação do cargo de bibliotecário. Como argumentação o autor desse projeto, Deputado Pedro Uczai, elencava: a) falta de bibliotecários na escola; b) a melhoria da

\footnotetext{
${ }^{2}$ Entre 2003 e 2010 Luíz Henrique da Silveira cumpriu dois mandatos.
} 
qualidade da educação no Estado; c) o desvio de professores para a biblioteca por faltar-Ihes formação específica. O Deputado menciona, ainda, a mobilização da categoria e das unidades escolares, ocorrida em 2005 e 2006, que abriu espaço para que o CRB-14 e a ACB viessem ocupar a tribuna da ALESC quando da entrega de milhares de assinaturas em defesa da biblioteca e do bibliotecário nas escolas catarinenses. Nesse PLC/0039.0/2010 (SANTA CATARINA, 2010) era prevista alteração da Lei no 1.139/1992 (SANTA CATARINA, 1992), que trata do Quadro do Magistério Público Estadual, por propor nela a inclusão do cargo de bibliotecário.

Aqui vemos ser retomado pelo Legislativo aquela ideia do Executivo de 2003, inclusive quanto ao número de cargos, isto é, trezentos. Esse projeto de lei foi aprovado e transformado em lei, contudo, com base no Parecer no PAR 0031/2011 (SANTA CATARINA, 2011), o Governo o declara inconstitucional.

Em outubro de 2011, durante a mesa de debate $A$ universalização de bibliotecas (Lei Federal no 12.244/2010) no Estado de SC, promovida pelo VII Fórum de Bibliotecas Escolares Estaduais, o Sindicato dos Trabalhadores em Educação da Rede Pública do Estado de Santa Catarina (SINTE/SC), manifesta-se que:

[...] o bibliotecário está contemplado na proposta de plano de carreira de cargos e salários do Sindicato dos Trabalhadores em Educação de Santa Catarina (SINTE-SC), pois os professores entendem o bibliotecário como uma figura intrínseca no magistério; no setor pedagógico. A escola precisa contar com o bibliotecário dentro do Projeto Político Pedagógico (PPP). [...] apesar da importância de ser implementada e regulamentada nos estados e municípios, a Lei no 12.244/2010 não prevê as formas de ter o bibliotecário nas bibliotecas das escolas. [...] uma educação de qualidade [...] se faz com bibliotecas. [...] luta para que as bibliotecas públicas - estaduais e municipais, tenham bibliotecários concursados com plano de carreira e com suas profissões regulamentadas e respeitadas. Sugeriu a realização de audiências públicas nas Regionais do Estado com o objetivo de se fazer diagnóstico das bibliotecas públicas. (GARCEZ, KIESER; FELÍCIO, 2012, p. 207).

Em dezembro de 2011, o Conselho Regional de Biblioteconomia (CRB-14) buscou conhecer a opinião de professores, diretores de escola e gerentes de educação sobre a biblioteca escolar e o bibliotecário. Garcez (2014, p. 13) que fez uso dos dados coletados mostra uma síntese do pensamento desses profissionais acerca desses temas que se entrelaçam - Escola, biblioteca, sala de aula, professor, bibliotecário: a) o bibliotecário tem competência para atuar na biblioteca das escolas; b) a organização do acervo, ênfase na leitura, contribuem para o incentivo à 
aprendizagem e está vinculada a uma orientação competente; c) a organização do acervo está associada ao acesso à informação; d) biblioteca é para todos da escola; e) o biliotecário na escola favorece o atendimento de uma rede de bibliotecas; f) o bibliotecário vem sendo reinvindicado pela escola.

Em 2013, durante a mesa-redonda O bibliotecário e as bibliotecas sob a ótica do gestor público, a Diretora de Educação Básica e Profissional (DIEP) da Secretaria de Educação (SED) comenta sobre um projeto de "reestruturação da Educação estadual catarinense e a inclusão do cargo de bibliotecário nas escolas do estado" (ASSOCIAÇÃO CATARINENSE DE BIBLIOTECÁRIOS, 2014, p. 36), momento em que havia...

pouco mais de mil [1.000] escolas geridas pelo Estado de Santa Catarina, e nenhuma delas possui o profissional bibliotecário atuando em seu corpo de funcionários. Na maioria dos casos, são professores readaptados que atuam nas bibliotecas escolares. Junto a diversos fatores, como a falta de uma política de estado efetiva para a educação, a leitura e a cultura, por exemplo, as bibliotecas escolares catarinenses não se desenvolveram ao ponto de atuar em rede e de forma planejada, ter seus acervos organizados e prestar serviços de informação especializados para professores, alunos e a comunidade em geral. (ASSOCIAÇÃO CATARINENSE DE BIBLIOTECÁRIOS, 2014, p. 9).

Das ações que envolveram os profissionais catarinenses para tratar das bibliotecas escolares, estas ocorrências tiveram implicação direta ao projeto de bibliotecas escolares ora exposto. Vale lembrar que desde a década de 1980, a Associação Catarinense de Bibliotecários (ACB) e o Conselho Regional de Biblioteconomia, 14a Região, tem organizado e participado de ações em prol da biblioteca escolar em Santa Catarina. O fato é que, decorridos tantos anos desde que a Reforma Trindade que em 1935 criou os cargos de professora bibliotecária e de professora encarregada de bibliotecas, o Estado tem descuidado de suas bibliotecas escolares.

\section{A biblioteca escolar possível: um projeto e suas justificativas}

Neste item ênfase será dada à proposta mais recente de um projeto bibliotecário para as bibliotecas das escolas estaduais de Santa Catarina, apresentado e entregue à Secretaria de Estado de Educação no início de 2013. A proposta possui três vertentes básicas: a) criação de 300 cargos de bibliotecário com o objetivo de viabilizar o funcionamento da rede proposta; b) vinculação do cargo ao Quadro do Magistério Público Estadual; c) alteração da Lei do Magistério Público Estadual, com a criação deste cargo e vinculação do mesmo ao quadro do magistério. 
Para a concepção desse projeto bibliotecário foram considerados: o número de escolas, o número de alunos nessas escolas, os órgãos descentralizados da Secretaria de Educação (36 distribuídos em 295 municípios para atender 1.112 escolas), a ausência de uma biblioteca em muitas escolas, a ausência de bibliotecário em todas as escolas, as diferentes nomenclaturas das escolas que oferecem ensinos da educação básica: EEB - Ensino Fundamental e Médio, EEM - Ensino Médio, EEF Ensino Fundamental, que repercutem no tamanho das mesmas, no quantiativo de alunos e na estrutura. Foram considerados para remodelar esse quadro: a) a criação do cargo do bibliotecário e sua vinculação no Quadro do Magistério por atuar na educação e não em outra secretaria do Governo; b) o reaproveitamento de professores readaptados para a formação das equipes de trabalho das bibliotecas escolares a fim de atender às escolas vinculadas às regionais; c) as competências do bibliotecário com base no tripé: gestão, técnica e atuação pedagógica. Portanto, tínhamos um diagnóstico situacional com base nas interlocuções que vinhamos mantendo com a Secretaria de Educação e de estudos elaborados pela categoria que também foram frutos dessas interlocuções.

$\mathrm{Na}$ sequência, discorremos sobre esses aspectos, elencando os pontos centrais dessa rede e justificativas.

\section{a)criação do cargo de bibliotecário}

As razões para a criação do cargo de bibliotecário para atender as escolas, seus profissionais e alunos já foram largamente expostas. Há muitos dados, inclusive do próprio governo federal de que nossas escolas precisam ser transformadas em espaços mais dinâmicos e a biblioteca é pensada como fundamental para leitura, letramento, pesquisa, ensino e aprendizagem. A Lei no 12.244 (BRASIL, 2010) é uma resposta que oferece um caminho para que o quadro melhore e compreendemos que o bibliotecário é um profissional que não pode faltar na rede de ensino e nas suas bibliotecas.

\section{b)definição do quantitativo}

A proposta de 2003 de origem do Executivo para a criação de 300 cargos de bibliotecário era compreendida como razoável e por isso permanecia nos discursos dos nossos interlocutores na Secretaria de Educação. Evidentemente, nos estudos anteriores não havia a Lei no 12.244 (BRASIL, 2010), mas a existência de escolas menores e até bem pequenas como as Escolas Isoladas ${ }^{3}$ poderiam vir a ser atendidas pelo trabalho de uma rede de bibliotecas. Na defesa deste quantitativo, estava a conhecida insuficiência de bibliotecários formados para atender 1.112 unidades escolares. Também sabíamos dos percalços que muitas escolas enfrentam com professores readaptados na biblioteca (BRASIL, 2011), contudo, pensou-se na possibilidade de contar com esses professores para formar a equipe das bibliotecas e também para atender aquelas

\footnotetext{
${ }^{3}$ Nomenclattura utilizada para definir pequenas escolas situadas em regiões afastadas das cidades. São escolas que atendem poucos alunos em diferentes anos do Ensino Fundamental, e juntos acabam formando as classes ou turmas multiseriadas.
} 
bibliotecas que não contariam com bibliotecário, já que este profissional também estaria enredado. Portanto, mesmo com 300 cargos de bibliotecário numa rede com mais de mil unidades escolares, é possível fazer funcionar a rede de bibliotecas. Nas Diretrizes sobre a Biblioteca Escolar, Ifla e Unesco (IFLA, 2002a, p. 11-12) evidenciam o trabalho em equipe que no contexto escolar refere-se a "um conjunto de bibliotecários habilitados e de técnicos de biblioteca. Deve haver também pessoas de apoio, como professores, técnicos, pais e outras categorias de voluntários."

c) vinculação do cargo ao Quadro do Magistério e desdobramentos

Tanto quanto o quantitativo de 300 cargos de bibliotecário, a vinculação do cargo de bibliotecário ao Magistério foi igualmente hipótese de iniciativa do Executivo em 2003. E esse mesmo entendimento era manifestado pelos atuais dirigentes da Secretaria de Estado da Educação em 2012. O bibliotecário atuará numa rede de educação e estará envolvido com as questões da escola e do ensino e realizará um trabalho conjunto com os professores e demais educadores da escola. É entendido que a sua vinculação neste quadro o inclui na equipe da escola, facilitando sua interação, integração e o trabalho cooperativo com toda a equipe. Essa vinculação ao Quadro do Magistério faz com que pensemos no uso dos mesmos critérios para definir a remuneração, a carga horária e o plano de carreira, cujo detalhamento encontra-se no Anexo A. Vale lembrar que os valores ali expostos são de 2012, portanto, carecem de atualização.

\section{d) critérios da distribuição dos cargos na rede proposta}

Com um quantitativo de 300 cargos para atender a rede proposta e vinculando-os à Diretoria de Educação Básica e Profissional (DIEB), o bibliotecário seria alocado em três postos de trabalho (órgão central, unidades regionais da SED e escolas). Para o órgão central o perfil está na função de gestor. Com um profissional vinculado à DIEB se estabeleceria uma interlocução mais estreita com as gerências vinculadas a esta diretoria, a saber: Gerência de Educação Profissional (GEDUP), Gerência de Educação de Jovens e Adultos (GEREJ), Gerência de Ensino Médio (GEREM) e Gerência e Ensino Fundamental (GEREF). Trinta e seis bibliotecários estariam distribuídos entre as 36 sedes das Secretarias Regionais da SED. Esses profissionais ficariam responsáveis pelo tratamento técnico dos acervos das escolas estaduais espalhadas pelos municípios vinculados a cada regional. Os demais bibliotecários, num total de 263 ocupariam os espaços das unidades escolares. Mas, quais das 1.112 escolas receberiam esses profissionais?

As escolas que receberiam bibliotecários deveriam enquadrar-se na seguinte condição: possuir mais de mil alunos, sendo que as escolas com mais de três mil alunos receberiam dois bibliotecários. Isso possibilitou a localização das escolas e os municípios que receberiam esse contingente de bibliotecários. São escolas centrais cujas nomemclaturas são: Escola de Educação Básica (EEB), Escola Ensino Médio (EEM), Instituto Estadual de Educação (IEE), este com mais de quatro mil alunos, Centro de Educação 
de Jovens e Adultos (CEJA), Escola de Ensino Fundamental (EEF) e Centro de Educação Profissional (CEDUP). O mapa com a distribuição dos cargos pode ser conferido no Anexo B.

\section{e) competências do bibliotecário}

Há no Anexo A um rol das competências do bibliotecário na rede proposta e essas competências estão articuladas às funções do bibliotecário no órgão central, nas regionais e nas unidades escolares.

Garcez (2014) tece longas considerações sobre as competências desse profissional, dando ênfase ao bibliotecário que atuará na escola pela sua aproximação ao fazer pedagógico e lúdico, em detrimento, por assim dizer, dos serviços de processamento técnico das coleções.

[...] ao atuar na escola, o bibliotecário precisará de outros conhecimentos além daqueles advindos de sua formação profissional. Parece-nos que dele serão exigidos conhecimentos do planejamento pedagógico da instituição, das disciplinas, dos alunos, dos professores, dos gestores da escola e das famílias dos alunos. Ou seja, da relação da biblioteca com questões próprias do meio escolar. [...] Portanto, o conhecimento advindo da formação e da atuação escolar e da vivência o ajudará nas práticas interativas com aqueles que estão na escola e no entorno desta. (GARCEZ, 2014, p. 12).

f) formação de uma rede de bibliotecas

O Projeto pautado no conceito de rede foi criando corpo à medida que ia avançando pela necessidade de dinamizar as bibliotecas escolares; criar o cargo de bibliotecário; fazer com que esse profissional não só se articule nas escolas, mas também fora dela, participando das discussões na Secretaria no que diz respeito ao livro, à leitura, aos planos que incluam a biblioteca na atividade do professor e das escolas.

Para estar na escola, foi previsto que o bibliotecário precisará ter uma interação mais dinâmica com os alunos. Portanto, como ficar concentrado no tratamento técnico do acervo? Parece-nos que uma atividade conflitua com a outra, exigem tempos e competências diferenciadas para um único profissional. Disso advém a necessidade de montar equipe de trabalho na biblioteca. Ifla e Unesco chamam a atenção para este detalhe que impacta no operacional e no qualitativo dos serviços. (IFLA, 2002a). Por isso, contar com professores para a formação dessa equipe é uma alternativa. Além das atividades administrativas, o professor poderá colaborar nas atividades de estímulo e acesso às leituras, bem como criar um espaço onde alunos, professores e outros atores da comunidade escolar possam encontrar respostas às suas necessidades de informação. Com o professor readaptado, o alcance da rede de bibliotecas será ampliado, integrando todas as escolas, não apenas as que receberão bibliotecários. Uma rede de unidades de informação escolar em pleno funcionamento, aliada à parceria com os 
professores, trará enorme impacto nos processos de ensino e aprendizagem.

\section{Considerações finais}

Espera-se que o projeto aqui socializado gere discussões em diferentes instâncias, nos pequenos e grandes grupos de gestores, políticos, bibliotecários, professores e demais membros da comunidade escolar, nas escolas de Biblioteconomia, nas reuniões que discutem o currículo da educação básica, daqueles que discutem especificamente a leitura e o livro, como por exemplo, o Programa Nacional de Incentivo à Leitura (PROLER) e o Plano do Livro e da Leitura em Santa Catarina, dentre outros.

Pensar numa rede de bibliotecas nos obrigou a pensar numa rede de profissionais para fazê-la funcionar. Uma rede de bibliotecas numa dimensão como a estadual, aqui proposta, requer um trabalho conjunto integrando diferentes profissionais envolvidos com a escola e com a educação. Este fundamento nos levou a discutir a criação do cargo de bibliotecário na esfera estadual para atender as necessidades de informação daqueles que frequentam as escolas do Estado de Santa Catarina. Esse entendimento também nos levou a discorrer sobre a distribuição desses cargos e as competências desse profissional, culminando no desenho ou estrutura da rede proposta. Com a reeleição do Governador $^{4}$ e permanecendo nessa Secretaria nossos principais interlocutores quando da concepção do projeto aqui socializado, vislumbra-se a continuidade do diálogo.

Se, "as escolas de Santa Catarina, por muito tempo, tiveram e ainda têm bibliotecas mortas, por falta de profissionais bibliotecários nestes espaços, livros, e ações pedagógicas" (GARCEZ; KIESER; SILVA, 2008, p. 515), por certo que a Secretaria de Estado da Educação precisa apresentar um plano de ação para que o quadro seja outro. Considerando o que dispõe a Lei no 12.244 (BRASIL, 2010), vale lembrar que faltam quatro anos para que o governo estadual apresente à sociedade catarinense um Plano para as suas BE.

O pronunciamento do SINTE/SC de que "apesar da importância de ser implementada e regulamentada nos estados e municípios, a Lei no 12.244/2010 [BRASIL, 2010] não prevê as formas de ter o bibliotecário nas bibliotecas das escolas" revela um possível indício de que há dúvidas na administração pública de estados e municípios quanto à aplicação dessa lei. É possível que ao prever peculiaridades contextuais dos estados e municípios brasileiros o Governo Federal delegue aos mesmos a decisão para que encontrem o melhor caminho para colocar a referida lei em prática. Neste sentido, insistimos que a categoria bibliotecária tem um projeto para as BE de Santa Catarina. Projeto que não prevê a permanência de um bibliotecário com dedicação exclusiva na maioria das escolas estaduais. Contudo, ele marca um início de um esforço para

\footnotetext{
${ }^{4}$ João Raimundo Colombo, eleito governador em 2010, reeleito para um segundo mandato em 2014.
} 
atender as necessidades dessa rede de ensino. Cremos que o governo estadual tem total competência e condições para desenvolvê-lo até 2020

\section{Referências}

ASSOCIAÇÃO CATARINENSE DE BIBLIOTECÁRIOS (ACB). Relatório final da gestão 2012-2013: "interferir, ressignificar, expandir". Organização e redação de José Paulo Speck Pereira. São José (SC), 2014. Disponível em: $<$ http://acb.emnuvens.com.br/wp-

content/uploads/2014/03/Relatorio final ACB 2012 20131.pdf $>$. Acesso em: 15 fev. 2015.

BOMBASSARO, T. Santa Catarina na IV Conferência Nacional de Educação por uma Escola Nova barriga-verde. Revista Brasileira de História da Educação, v. 1, n. 3, p. 137-173, set./dez. 2007. Disponível em: $<$ http://www.rbhe.sbhe.org.br/index.php/rbhe/article/view/124/134>.

Acesso em: 14 jun. 2015.

BRASIL. Decreto-Lei no 8.529, de 02 de janeiro de 1946. Dispõe sôbre a adaptação dos serviços do ensino primário nos Estados, Territórios e Distrito Federal, a Lei Orgânica do Ensino Primário. Disponível em: <http://www2.camara.leg.br/legin/fed/declei/1940-1949/decreto-lei8585-8-janeiro-1946-416400-norma-pe.html>. Acesso em: 14 jun. 2015.

BRASIL. Lei no 12.244, de 24 de maio de 2010. Dispõe sobre a universalização das bibliotecas nas instituições de ensino do País. Diário Oficial [da] República Federativa do Brasil, Brasília, DF, 25 maio 2010. Disponível em: <http://www.planalto.gov.br/ccivil 03/ Ato20072010/2010/Lei/L12244.htm>. Acesso em: 17 fev. 2015.

BRASIL. Ministério da Educação. Avaliação das bibliotecas escolares no Brasil. 1.ed. São Paulo: Edições SM, 2011. 112p. (CEIDEA Coleção de Estudos). Disponível em: <http://www.oei.es/bibliobrasil.pdf $>$. Acesso em: 26 jul. 2014.

BRASIL. Ministério da Educação. Programa Nacional Biblioteca da Escola (PNBE): leitura e biblioteca nas escolas públicas brasileiras. Brasil: MEC, 2008. Disponível

em: $<$ http://portal.mec.gov.br/seb/arquivos/pdf/Avalmat/livro mec final baix a.pdf>. Acesso em: 29 jul. 2014.

EGGERT-STEINDEL, G.; FONSECA, C. F. A biblioteca escolar: participante da promoção da justiça e êxito escolar. In: VALLE, I. R.; SILVA, V. L. G.; DAROS, M. D. (Org.). Educação escolar: justiça social. Florianópolis: Ed. UFSC, 2010. p. $249-271$.

FÓRUM ESTADUAL DE BIBLIOTECAS ESCOLARES, 3., Florianópolis, 18 out. 2003. Rev. ACB: Biblioteconomia em Santa Catarina, v. 8/9, p. 79, $2003 / 2004$. <http://www.revista.acbsc.org.br/racb/article/view/407/514>. Acesso em: 16 fev. 2015. 
FREIRE, P. A importância do ato de ler: em três artigos que se completam. 35. ed. São Paulo: Cortez, 1997. (Questões da Nossa Época, 13).

GARCEZ, E. F. As competêcias do bibliotecário na educação básica: reflexões a partir de proposta de rede. Perspectivas em Ciência da Informação, Belo Horizonte, v. 19, n. 4, p. 3-24, out./dez. 2014. Disponível em: <http://portaldeperiodicos.eci.ufmg.br/index.php/pci/article/view/1923/1 517>. Acesso em: 4 jan. 2015.

GARCEZ, E. F.; KIESER, H.; FELÍCIO, J. C. de S. M. Relatório do VII Fórum Estadual de Bibliotecas Escolares: Florianópolis, 8 de outubro de 2011. Rev. ACB: Biblioteconomia em Santa Catarina, Florianópolis, v.17, n.1, p. 194-209, jan./jun. 2012. Disponível em: <http://revista.acbsc.org.br/racb/article/view/838/pdf 79 >. Acesso em: 8 jan. 2015.

GARCEZ, E. F.; KIESER, H. ; SILVA, I. J. da. Relatório do V Fórum Estadual de Bibliotecas Escolares: Joinville, 21 de outubro de 2006. Rev. ACB: Biblioteconomia em Santa Catarina, Florianópolis, v. 13, n. 2, p. 503-522, jul./dez. $2008 . \quad$ Disponível em: <http://revista.acbsc.org.br/racb/article/view/615/697>. Acesso em: 08 jan. 2015.

IFLA. Diretrizes da IFLA/UNESCO para a biblioteca escolar. 2002a. Disponível em: <http://www.ifla.org/files/assets/school-librariesresource-centers/publications/school-library-guidelines/school-libraryguidelines-pt br.pdf>. Acesso em: 26 jul. 2014.

IFLA. Diretrizes para o Manifesto IFLA/UNESCO sobre a internet. 2006. < http://www.ifla.org/files/assets/faife/publications/policy-documents/internetmanifesto-guidelines-pt.pdf >. Acesso em: 10 jun. 2016.

IFLA. Manifesto IFLA/UNESCO para a biblioteca escolar. 1999. Disponível em: <http://www.cultura.al.gov.br/politicas-e-acoes/sistema-estadual-debibliotecas-publicas/leituras-

recomendadas/BIBLIOTECAS $\% 20$ ESCOLARES $\% 20 M A N I F E S T O \% 20 D A \% 20$ IFLA.pdf>Acesso em: 17 fev. 2015.

IFLA. Manifesto sobre internet. 2002b. Disponível em: $<$ http://www.ifla.org/files/assets/faife/publications/policy-documents/internetmanifesto-pt.pdf >. Acesso em: 08 jun. 2016.

IRELAND, V. (Coord.). Repensando a escola: um estudo sobre os desafios de aprender, ler e escrever. Brasília: UNESCO; MEC/INEP, 2007. 331 p. Disponível em: <http://unesdoc.unesco.org/images/0015/001512/151253por.pdf>.

Acesso em: 14 ago. 2010.

MACHADO, A. A implantação de bibliotecas escolares na rede de ensino de Santa Catarina (décadas de 30 e 40). 2002. 132 f. Dissertação (Mestrado 
em Educação e Cultura) - Centro de Ciências da Educação, Universidade do Estado de Santa Catarina, Florianópolis, 2002.

MIGNOT, Ana Chrystina Venâncio. Baú de Memórias, Bastidores de Histórias: o legado pioneiro de Armanda Álvaro Alberto. Bragança Paulista/SP: EDUSF, 2002.

SANTA CATARINA. Assembleia Legislativa do Estado de Santa Catarina. Lei Complementar Promulgada no 1.139, de 28 de outubro de 1992. Dispõe sobre cargos e carreiras do Magistério Público Estadual, estabelece nova sistemática de vencimentos, institui gratificações e dá outras providências. Disponível em: <file:///C:/Users/Usuario/Downloads/Lei\%20N\%201.139,\%20de\%2028\%20de\%200 utubro\%20de\%201.992\%20-\%20c alteracoes\%20posteriores\%20(1).pdf $>$. Acesso em: 14 jun. 2015.

SANTA CATARINA. Assembleia Legislativa do Estado de Santa Catarina Relatório e voto ao projeto de Lei Complementar no PCL/0039.0/2010. Disponível em: <http://alesc.sc.gov.br/proclegis/tramitacao.php>. Acesso em: 22 jun. 2012.

SANTA CATARINA. Decreto no. 3.735, de 17 de Dezembro de 1946. Regulamento para os estabelecimentos de ensino primário no Estado de Santa Catarina. Santa Catarina, 1946. 153 p.

SANTA CATARINA. Lei no 6.844, de 29 de julho de 1986 . Dispõe sobre o Estatuto do Magistério Público Estadual do Estado de Santa Catarina. Disponível em: <http://webcache.googleusercontent.com/search?q=cache:iVTJZfsL1dsJ:www.sea.s c.gov.br/index.php\%3Foption\%3Dcom docman\%26task\%3Ddoc download\%26gid $\% 3 D 749 \% 26$ lang\%3D+\&cd=1\&hl=pt-BR\&ct=clnk\&gl=br $>$. Acesso em: 08 jun. 2016.

SANTA CATARINA. Procuradoria Geral do Estado. Parecer 0031/11, de 06 de janeiro de 2011. (Cópia fornecida pelo Centro de Memória, da Coordenadoria de Documentação, da Assembleia Legislativa do Estado de Santa Catarina - ALESC).

SANTA CATARINA. Secretaria de Estado da Educação e Inovação. Diretoria de Recursos Humanos. Portaria no 003/SED de 04/04/2003. Dispõe sobre o pessoal para desenvolver atividades administrativas nas EEM - EEB EEF da rede estadual de ensino. Diário Oficial [do Estado de Santa Catarina], Florianópolis, p. 2, 8 abr. 2003.

SILVA, J. F. M. ; SIQUEIRA, I. Biblioteca escolar como uma questão de direitos humanos. Bibl. Esc. em R., Ribeirão Preto, v. 3, n. 1, p. 38-50, 2014. <http://revistas.ffclrp.usp.br/BEREV/article/viewFile/326/pdf>. Acesso em: 14 fev. 2015.

SILVA, W. C. Miséria da biblioteca escolar. São Paulo: Cortez, 1995. (Questões da Nossa História, 45). 
VIDAL, D. G. O exercício disciplinado do olhar: livros, leituras e práticas de formação docente no Instituto de Educação do Distrito Federal (19321937). 1995. 230 f. Tese (Doutorado em Educação) - Programa de PósGraduação em Educação, Universidade de São Paulo, 1995.

\section{Agradecimentos}

Os autores deste texto, e que integraram a comissão de estudo do projeto aqui exposto, fazem aqui um expresso agradecimento à Ana Lúcia Zaia Costa, Ana Luiza de Oliveira Mattos, Elisa Cristina Delfini Correa, Elizabeth Braga Moreira, Francisca Rasche, Francisco das Chagas de Souza, Herta Kieser, Inês Josino da Silva, Josias do Rosário, Magda Teixeira Chagas, Maria de Lourdes Blatt Ohira, Marli Machado, Miriam de Cassia do Carmo Mascarenhas Mattos, Rosálvio José Sartott, Salete Cecília de Souza, Ursula Blatmann, e demais colegas da Associação Catarinense de Bibliotecários ( $A C B$ ), do Conselho Regional de Biblioteconomina (CRB14), do Grupo de Bibliotecários da Área Escolar de Santa Catarina (GBAE/SC), dos cursos de Biblioteconomia da Universidade Federal de Santa Catarina (UFSC) e da Universidade do Estado de Santa Catarina (UDESC) por não medirem o uso do seu tempo profissional e pessoal neste árduo trabalho de formigas incansáveis do movimento em prol da biblioteca escolar em Santa Catarina.

\section{Complementar ${ }^{5}$ \\ ANEXO $A$ - O projeto bibliotecário em um Projeto de Lei}

\section{PROJETO DE LEI COMPLEMENTAR No XXXX}

Transforma cargos do Anexo IX, da Lei no 1.139 de 28 de outubro de 1992 em cargos de Bibliotecário Escolar e dá outras providências.

CATARINA,

\section{O GOVERNADOR DO ESTADO DE SANTA}

Faço saber a todos os habitantes deste Estado que a Assembléia Legislativa decreta e eu sanciono a seguinte Lei:

Art. $1^{0}$ Ficam transformados 300 (trezentos) cargos de Professor do Anexo IX em Bibliotecário Escolar, do Quadro do Magistério Público Estadual - MAG, e transpostos do quantitativo de cargos previstos no Anexo IX para o Anexo XVIII da Lei no 1.139, de 28 de outubro de 1992, criado nesta Lei Complementar.

$$
\text { Art. } 2^{0} \text { - O Art. } 1^{0} \text { da Lei no 1.139, de } 28 \text { de }
$$
outubro de 1992, fica acrescido do seguinte inciso:

\footnotetext{
${ }^{5}$ Conforme mencionado na introdução deste artigo, a proposta de criação do cargo de bibliotecário vinculado ao quadro do Magistério (Lei no 1.139/1992), faz com que anexos dessa lei sofram alterações, ou seja, em sendo aceito o projeto de lei proposto pela categoria, seus anexos I, II, III, IV, V e VI alteram respectivamente os anexos XVIII, XIX, XX, XXI, XXII e XXIII da Lei 1139/1992.
} 
"Art. 10

\section{VI - Bibliotecário Escolar."}

Art. 30 A Lei no 1.139, de 28 de outubro de 1992, fica acrescida dos Anexos XVIII, XIX, XX, XXI, XXII e XXIII, constando o quantitativo, as habilitações, as atribuições, a carga horária, a distribuição e o vencimento do cargo de Bibliotecário Escolar, conforme disposto nos Anexos I, II, III, IV, V e VI desta Lei Complementar.

Art $4^{\circ} \mathrm{O}$ vencimento do cargo de que trata esta Lei Complementar é o fixado em níveis e referências segundo os valores constantes do Anexo VI, da Lei n. 1.139, de 28 de outubro de 1992, com as alterações posteriores.

Art $5^{\circ}$ Os ocupantes do cargo de Bibliotecário Escolar terão atuação nas escolas da rede pública estadual, Secretarias do Desenvolvimento Regional, e Órgão Central da Secretaria de Estado da Educação.

Parágrafo único - Os critérios de distribuição dos cargos de que trata esta Lei Complementar serão definidos em regulamento próprio, por decreto do Chefe do Poder Executivo.

Art. $6^{\circ}$ As despesas decorrentes da execução desta Lei correrão à conta dos recursos consignados no orçamento geral do Estado.

publicação.

Art 70 Esta Lei entra em vigor na data de sua

Florianópolis, xx, de xxxxx de 2012.

João Raimundo Colombo

Governador do Estado de Santa Catarina 
ANEXO I

Anexo XVIII

Lei no 1.139, de 28 de outubro de 1992

GRUPO: MAGISTÉRIO - MAG

\begin{tabular}{|c|c|c|c|}
\hline CARGO & $\begin{aligned} \text { NO } & \text { DE } \\
\text { CARGOS } & \end{aligned}$ & ÍVEL & HABILITAÇÃO PROFISSIONAL \\
\hline $\begin{array}{l}\quad \text { BIBLIOT } \\
\text { ECÁRIO } \\
\text { ESCOLAR }\end{array}$ & 300 & $\begin{array}{l}8 \\
9\end{array}$ & \begin{tabular}{l}
\multicolumn{3}{c}{ Bacharelado em curso Superior } \\
de Biblioteconomia com registro no \\
Conselhor Regional \\
Biblioteconomia desta jurisdição.
\end{tabular} \\
\hline & & $\begin{array}{l}0 \\
1\end{array}$ & \begin{tabular}{l}
\multicolumn{3}{c}{ Bacharelado em curso Superior } \\
de Biblioteconomia com registro no \\
Conselho \\
Biblioteconomia desta jurisdição, e \\
curso de \\
(Especialização, \\
Doutorado).
\end{tabular} \\
\hline
\end{tabular}

ANEXO $I I^{7}$

Anexo XIX

Lei no 1.139, de 28 de outubro de 1992

GRUPO: MAGISTÉRIO - MAG

DESCRIÇÃO DAS ATRIBUIÇÕES DO CARGO

DENOMINAÇÃO DO CARGO: BIBLIOTECÁRIO ESCOLAR

LOTAÇÃO/ATUAÇÃO: ORGÃO CENTRAL

DESCRIÇÃO SUMÁRIA

Participar do planejamento das decisões da Secretaria de Estado da Educação voltadas às políticas de leitura e uso da informação nas escolas. Manter estreita interlocução com os bibliotecários lotados na SDR, e, por intermédio destes, com os que atuam nas escolas sendo seu representante na Secretaria. (Atividades de Gestão).

DESCRIÇÃO DETALHADA

Definir políticas de atuação do bibliotecário escolar na rede estadual de bibliotecas escolares junto à Secretaria de Estado da Educação;

Planejar a atuação da rede de bibliotecas e informação em nível local, regional e estadual;

\footnotetext{
${ }_{7}^{6}$ Anexo 1 do projeto de lei proposto pela categoria, se aprovado, altera o anexo XVIII da Lei 1.139/1992.

${ }^{7}$ Anexo 2 do projeto de lei proposto pela categoria, se aprovado, altera o anexo XIX da Lei 1.139/1992.
} 
Promover, de forma integrada, o planejamento da política de seleção e de aquisição de acervo na unidade central e nas bibliotecas das escolas;

Elaborar, de forma participativa, as políticas dos serviços das bibliotecas, definindo objetivos e prioridades de acordo com os diferentes contextos das unidades escolares;

Definir políticas de acesso à informação nas bibliotecas escolares;

Desenvolver diretrizes para a prática da pesquisa escolar e técnica bibliográfica;

Incentivar o desenvolvimento de projetos de incentivo à leitura e atividades culturais;

Interagir com os bibliotecários lotados nas SDR e nas unidades escolares conhecendo seus diferentes contextos a fim de apoiar as atividades meio e fim da rede de bibliotecas escolares;

Planejar a política de tratamento e organização do acervo (catalogação, classificação, indexação) das bibliotecas escolares; escolares;

Elaborar Diretrizes de disseminação da informação nas bibliotecas

Criar Política de seleção, remanejamento, preservação, e descarte do acervo no âmbito das bibliotecas das unidades escolares da rede estadual de educação;

Participar da elaboração da política orçamentária incluindo nela as necessidades da rede de bibliotecas escolares.

JORNADA DE TRABALHO: 40 (quarenta) horas semanais.

ANEXO $I I I^{8}$

Anexo XX

Lei no 1.139 , de 28 de outubro de 1992

GRUPO: MAGISTÉRIO - MAG

DESCRIÇÃO DAS ATRIBUIÇÕES DO CARGO

DENOMINAÇÃO DO CARGO: BIBLIOTECÁRIO ESCOLAR

LOTACAO/ATUAÇÃO: SECRETARIAS DE DESENVOLVIMENTO REGIONAL

DESCRIÇÃO SUMÁRIA

Assessorar, no que tange às questões técnicas e gerenciais, os bibliotecários com atuação nas unidades escolares integrantes da SDR bem como representar estes profissionais perante o Órgão Central. (Exercício de atividades meio).

DESCRIÇÃO DETALHADA

Participar da definição de políticas de atuação do bibliotecário da rede de bibliotecas escolares junto à Secretaria de Estado da Educação;

Manter-se informado sobre as condições das bibliotecas das unidades escolares vinculadas à SDR pela qual é responsável;

\footnotetext{
${ }^{8}$ Anexo 3 do projeto de lei proposto pela categoria, se aprovado, altera o anexo XX da Lei 1.139/1992.
} 
Participar dos cursos, reuniões, palestras e demais eventos relacionados à sua área de atuação;

Participar, quando convidado, dos encontros e reuniões promovidos pela Secretaria de Estado da Educação;

Manter-se informado das condições de trabalho dos bibliotecários das unidades escolares vinculadas à SDR, onde é lotado;

Representar perante o Órgão Central os bibliotecários lotados nas unidades escolares vinculadas à SDR onde é lotado;

Assessorar os bibliotecários quanto às questões técnicas;

Colaborar com o Órgão Central no tocante à definição e execução da política de seleção, remanejamento, preservação, e descarte do acervo no âmbito das bibliotecas das unidades escolares da rede estadual de educação;

Participar da elaboração das políticas dos serviços das bibliotecas, respeitando os diferentes contextos escolares;

Participar da definição de política de acesso à informação nas bibliotecas escolares;

Manter estreita interação com os demais bibliotecários lotados nas SDR para a melhor consecução das atividades meio e fim da rede de bibliotecas escolares;

Desenvolver diretrizes para a prática da pesquisa escolar e técnica bibliográfica;

Participar do planejamento da política de tratamento e organização dos acervos (catalogação, classificação, indexação) das bibliotecas escolares;

Executar atividades técnicas voltadas ao controle, tratamento e organização dos acervos (catalogação, classificação, indexação) das bibliotecas escolares;

Participar da elaboração das Diretrizes de disseminação da informação no âmbito das bibliotecas das unidades escolares;

Participar da elaboração da política orçamentária integrando nela a rede de bibliotecas escolares.

JORNADA DE TRABALHO: 40 (quarenta) horas semanais.

ANEXO IV ${ }^{9}$

Anexo XXI

Lei no 1.139, de 28 de outubro de 1992

GRUPO: MAGISTÉRIO - MAG

DESCRIÇÃO DAS ATRIBUIÇÕES DO CARGO

DENOMINAÇÃO DO CARGO: BIBLIOTECÁRIO ESCOLAR

LOTACAO/ATUAÇÃO: UNIDADES ESCOLARES

DESCRIÇÃO SUMÁRIA

Desenvolver atividades de incentivo à leitura, de difusão e disseminação de informações nas unidades escolares, envolvendo-se com

\footnotetext{
${ }^{9}$ Anexo IV do projeto de lei proposto pela categoria, se aprovado, altera o anexo XXI da Lei 1.139/1992.
} 
as atividades curriculares e extra-curriculares da escola, e atendendo também a comunidade local (Exercício de Atividades fim).

\section{DESCRIÇÃO DETALHADA}

Apoiar e intensificar a consecução dos objetivos educacionais definidos na Proposta Curricular do Estado de Santa Catarina, no currículo e no Projeto Político Pedagógico da escola;

Oferecer à comunidade escolar oportunidade de vivências destinadas à produção e uso da informação voltadas ao conhecimento, à compreensão, imaginação e ao entretenimento;

Desenvolver serviços de orientação ao leitor;

Promover o acesso às fontes de informação nos suportes impresso, eletrônico e disponíveis na internet;

Apoiar e orientar os alunos para que desenvolvam as habilidades de uso da informação independentemente da forma e do suporte em que esteja registrada;

Organizar atividades que incentivem a tomada de consciência cultural e social, bem como de sensibilidade, promovendo exposições, saraus, concursos, oficinas, palestras e outros, em conformidade com a Proposta Curricular do Estado de Santa catarina, com o Projeto Político Pedagógico da Escola e com a cultura local;

Trabalhar em conjunto com os alunos, professores, administradores e familiares, para o alcance final da missão e objetivos da escola;

Atuar em rede com os demais bibliotecários, promovendo a cooperação, compartilhamento, trânsito e melhoria de uso de informação na escola e fora dela;

Indicar sugestões para a aquisição do acervo, visando a sua constante atualização;

Participar da elaboração da política de seleção e de aquisição de acervo;

Incentivar a cooperação entre os diferentes atores da comunidade escolar e de outros grupos da comunidade local onde a biblioteca está inserida;

Auxiliar professores e alunos na prática da pesquisa escolar e técnica bibliográfica;

Promover atividades de ação cultural;

Participar das reuniões pedagógicas e demais atividades desenvolvidas pela escola;

Trabalhar para a inclusão da biblioteca escolar nas atividades pedagógicas;

Participar das reuniões promovidas pela escola, pela SDR e pela Secretaria de Educação do Estado;

Participar de cursos de formação continuada.

JORNADA DE TRABALHO: 40 (quarenta) horas semanais. 


\section{ANEXO $\mathrm{V}^{\mathbf{1 0}}$}

Anexo XXII

Lei no 1.139, de 28 de outubro de 1992

GRUPO: MAGISTÉRIO - MAG

CRITÉRIOS DE DISTRIBUIÇÃO

\begin{tabular}{l}
\hline \multicolumn{2}{|l|}{ DENOMINAÇÃO DO CARGO: BIBLIOTECÁRIO ESCOLAR } \\
\begin{tabular}{|l|l|l|}
\hline LOTAÇÃO/ATUAÇÃO & QUANTITATIVO & CARGA HORÁRIA \\
\hline Órgão Central & 1 & $40 \mathrm{~h}$. \\
\hline SDR & 36 & $40 \mathrm{~h}$. \\
\hline Unidades Escolares & 263 & $40 \mathrm{~h}$. \\
\hline
\end{tabular}
\end{tabular}

ANEXO VI $I^{11}$

Anexo XXIII

Lei no 1.139, de 28 de outubro de 1992

GRUPO: MAGISTÉRIO - MAG

TABELA DE VENCIMENTOS

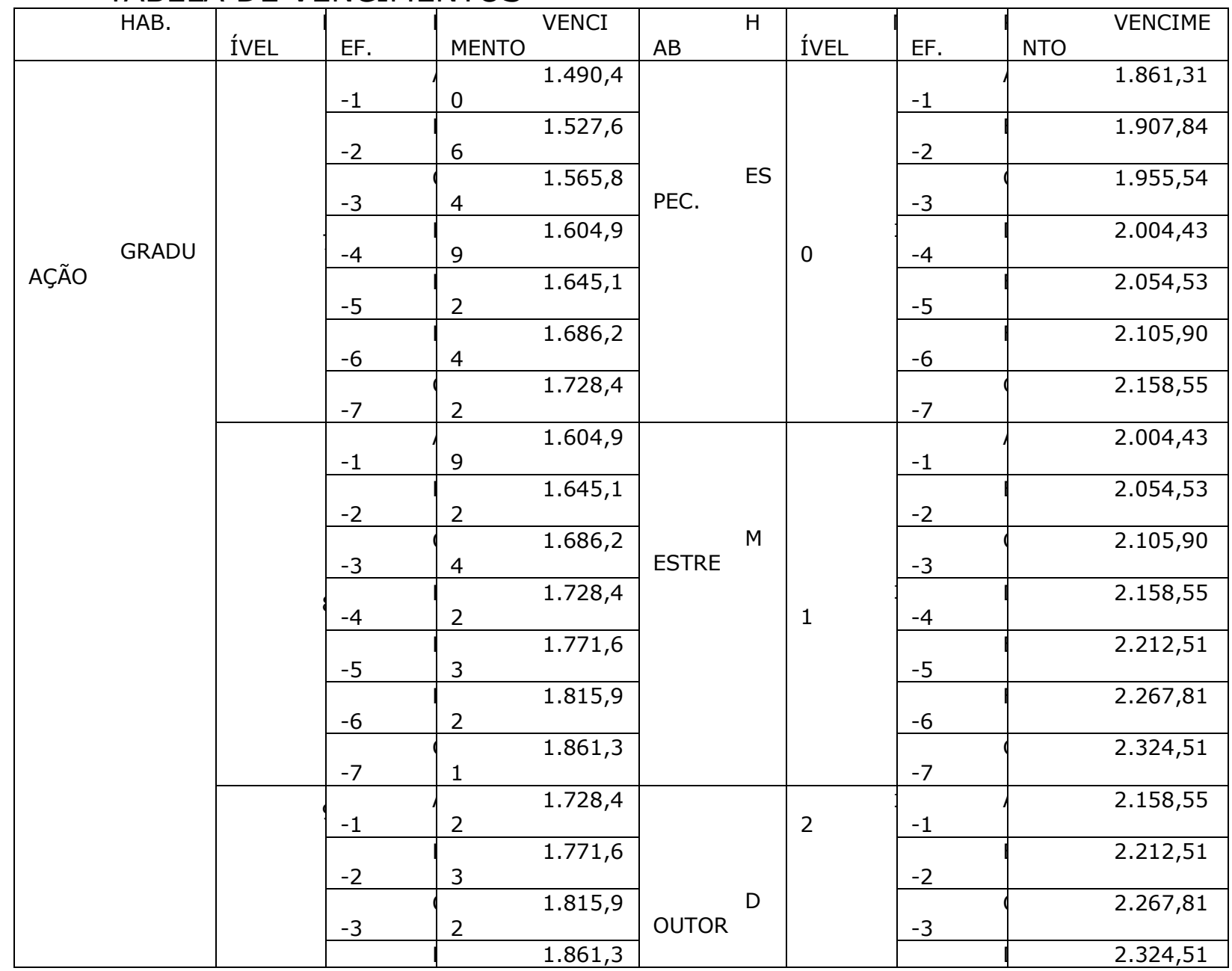

\footnotetext{
${ }_{11}^{10}$ Anexo $\mathrm{V}$ do projeto de lei proposto pela categoria, se aprovado, altera o anexo XXII da Lei 1.139/1992.

11 Anexo VI do projeto de lei proposto pela categoria, se aprovado, altera o anexo XXIII da Lei 1.139/1992.
} 
Um projeto de rede de bibliotecas para as escolas públicas estaduais De Santa Catarina, Brasil: relato de experiência(s)
Eliane Fioravante Garcez; Gisela EggertSteindel; José Paulo Speck Pereira; Gyance

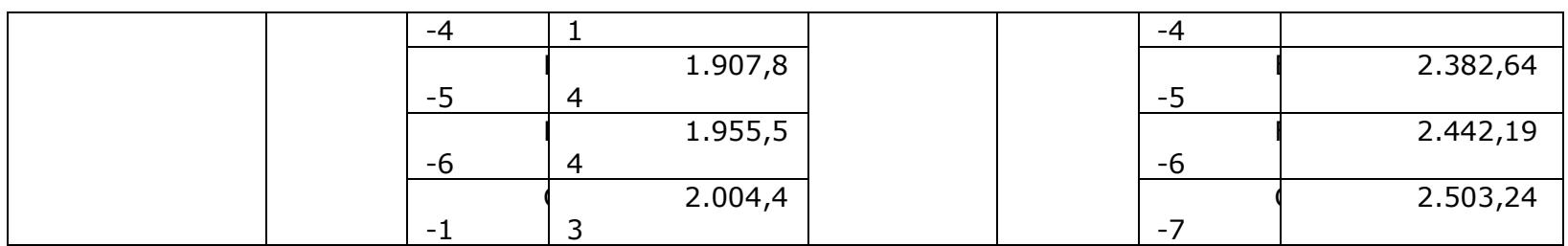

\section{ANEXO B - Mapa da distribuição de 300 bibliotecários na rede proposta}

Conselho Regional de Biblioteconomia da 14a Região Associação Catarinense de Bibliotecários Grupo de Bibliotecários de Área Escolar de SC
Bibliotecários na Rede Estadual de Educação de Santa Catarina

Mapa 1: Articulação entre o bibliotecário lotado na Secretaria de Estado da Educação com os bibliotecários lotados nas SDR/GERED.

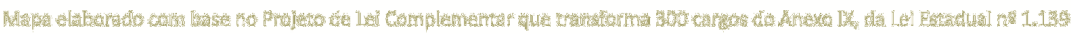

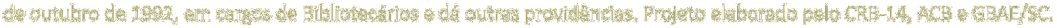

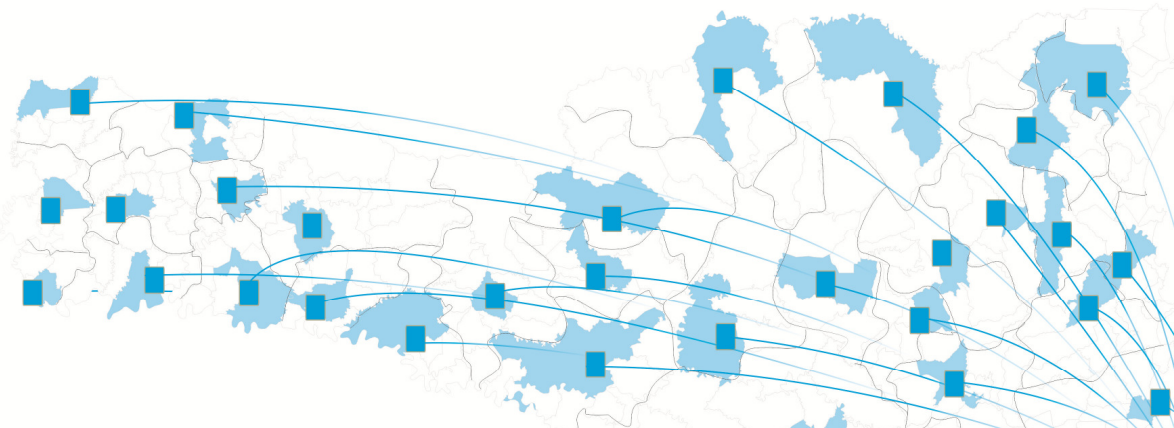

Título: Mapa da distribuição de bibliotecários na Rede de Bibliotecas Escolares proposta para Santa Catarina

Fonte: Dos autores (2015). 